IRSTI 28.17.23

https://doi.org/10.26577/phst.2021.v8.i2.04

\title{
Simulation of non-isothermal liquid sprays under large-scale turbulence
}

\author{
A. Askarova ${ }^{1}$ iD , S. Bolegenova ${ }^{1}$ (D), Sh. Ospanova ${ }^{1 *}$ iD, \\ N. Slavinskaya ${ }^{2}$ iD, A. Aldiyarova $^{1}$ (D) and N. Ungarova ${ }^{1}$ iD \\ 'Physics and Technology Department, Al-Farabi Kazakh National University, Almaty, Kazakhstan \\ ${ }^{2}$ Institute of Combustion Technology, German Aerospace Centre (DLR), Stuttgart, Germany \\ "e-mail: Shynar.Ospanova@kaznu.kz
}

\begin{abstract}
Due to the high level of achieved research, there are prospects for the widespread use of the method and specific physical results in the areas under consideration, as well as ways for more effective application of mathematical modeling methods using modern computing technology in various subject areas. For the numerical study of the combustion of liquid fuels, it is required to consider many complex interrelated processes and phenomena, which are laborious tasks of computational thermal physics. In the theory's study of combustion and the development of various technical devices, the actions of which are based on the use of the combustion process, a computational experiment is becoming an increasingly important element. Computational fluid dynamics methods have become widespread in technical physics when it becomes possible to optimize an experiment based on its virtual prototype. This work is devoted to the numerical modeling of the processes of breakup, dispersion, evaporation and combustion of liquid fuel droplets under high turbulence. Fundamental characteristics, methods of liquid fuels atomization, the mathematical model and basic equations describing the collision, distribution and combustion of liquid fuels at high turbulence are presented. Results of computational experiments by determination of the optimal conditions for the combustion of liquid hydrocarbon fuel are presented. Influence of the oxidant's initial temperature on the processes of atomization and dispersion of droplets in the combustion chamber under high turbulence is investigated. Optimal combustion parameters for the dodecane have been determined.
\end{abstract}

Key words: numerical modeling, atomization, liquid fuel, dodecane, high turbulence.

PACS number: 07.05.Tp.

\section{Introduction}

One of the main global problems of the urbanized countries including Kazakhstan, is the emission of pollutants into the atmosphere. Almaty is the city of Kazakhstan with the greatest traffic congestion. The Statistics Department of Almaty fixes the increased concentration of harmful substances (small suspended particles) in the air on a weekly basis. Small suspended particles PM2.5 and PM10 are in the atmosphere as an aerosol; because of their low weight, they can't settle to the ground. The World Health Organization PM10 and PM2.5 are classified as priority pollutants. PM2.5 particles are actually soot, dust, micro-fragments of asphalt and rubber, mineral salts (sulfates, nitrates) and heavy metal compounds (mainly oxides). They are got because of the work of some industries, but often an increase in their concentration is provoked by cars, namely the combustion of liquid fuel [1-6].

The course of chemical reactions under conditions of dynamic and thermal interaction of reagents, phase transformations accompanying intensive mass transfer of reagents, the influence of the thermodynamic state of the system and its structural characteristics on the process parameters are the distinctive features of the combustion of liquid fuels. The problem of fundamental research of the regularities of heat and mass transfer processes during the combustion of various types of liquid fuel requires a detailed study of the theory of combustion.

A lot of problems arising in thermal physics and technical physics associate with the numerical solution of the Navier-Stokes equations systems, which is the basis of continuum mechanics. 
Therefore, in connection with the ever-increasing use of numerical research in solving scientific and technical problems, it is important to ensure the greatest possible scientific and practical side of the issue. It can only achieve this through careful application of numerical modeling methods in various subject areas. [7, 8].

The efficiency of fuel use, and, ultimately, the productivity and environmental friendliness of the installation, depends on the correct (optimal) organization of fuel combustion, including the processes of fuel preparation, fuel supply and rational combustion. All research on creating efficient internal combustion engines is aimed at reducing the amount of pollutants emitted by vehicles into the atmosphere. Emissions from gasoline and diesel internal combustion engines contain carbon dioxide $\left(\mathrm{CO}_{2}\right)$ and carbon monoxide (CO). Partially combusted fuels are also present in the exhaust gases, which form a complex mixture of hydrocarbons (HCs) such as methane $\left(\mathrm{CH}_{4}\right)$. Also, in the composition of combustion products, solid particles and nitrogen oxides $\left(\mathrm{NO}_{\mathrm{x}}\right)$ are emitted, the latter are a common component of diesel emissions $[9,10]$.

Organization of high-quality combustion of fuel largely influences the problems of saving energy resources and improving the ecological state of heat engines. However, the technologies for the preparation and combustion of fuel are practically brought to perfection, and the efficiency and environmental cleanliness of internal combustion engines in most cases leaves much to be desired. The problem arises from searching for new methods in this area. Modeling of breakup, dispersion, evaporation and combustion processes of liquid fuel droplets under various initial conditions applies to solving the posed problems.

Since 2019, any vehicle for public roads imported into the Republic of Kazakhstan permanently and from the countries of the Customs Union must comply with the Euro-5 standard. Using fuel inappropriate for the ecological class by vehicles leads to premature wear of vehicle exhaust systems and unjustified costs for consumers of equipment. Engines with a fuel analyzer under the Euro 5 standard create difficulties in operation outside of large cities where low quality fuels are used. Here, it automatically reduced the engine speed until it stops completely. Besides the obvious positive environmental effect, the entry into force of stricter regulations will stimulate the production of more modern types of vehicles and introducing technologies in engine building. In addition, there is an opportunity to create new industries in the automotive industry, primarily in the production of components and components.

Also, since January 1, 2018, Kazakhstan has completely switched to the use of motor fuel of environmental standards not lower than Euro-4 and Euro-5. Now gasoline and diesel fuel supplied at retail must comply with the $\mathrm{K} 4$ and K5 environmental classes. Using these fuels will reduce emissions of harmful substances $[11,12]$.

In connection with the above, intensification of production, decrease in the material consumption of equipment, an economical consumption of fuel and environmental protection are gaining special significance and relevance. It is very important to create a scientific basis for intensive technological processes that ensure the integrated use of fuel and its waste, excluding the harmful effects of production on the biosphere. The new strategy for nature protection and energy conservation involves the selection of the most effective achievements of scientific and technological progress. Three major groups of measures stand out among them: utilization, energy modernization and intensive energy saving.

On July 1, 2021, a new Environmental Code will come into force in Kazakhstan, which complies with international legislative standards in environmental protection. Kazakhstan has become the first country in the post-Soviet space where the idea of a "green economy" is being implemented. On May 30, 2013, Government approved the Concept for the Transition of the Republic of Kazakhstan to a Green Economy.

For a comprehensive experimental study of two-phase flows, it becomes necessary to use special equipment and special working bodies (it is necessary to form a flow of drops of a certain size and a component composition), as well as to develop and use special methods for measuring flow parameters and corresponding measuring equipment, which complicates this process. The development of mathematical modeling of these types flows and the modern power of electronic computers make it possible to a certain extent to get data on the behavior of a two-phase flow, but without obtaining experimental data that allow checking the mathematical models used, it is impossible to verify the adequacy of their application and the accuracy of the results. In the light of such difficulties, phenomenological models of such flows are increasingly being applied. 
The engines of the current generation of cars differ significantly from those that were used several decades ago. The main combustion process in engines remains the same, but the injections differ significantly.

Modern internal combustion engines use hightech fuel injectors to deliver fuel to the engine in the most efficient way. There are different fuel injection systems depending on the type of engine. The most commonly used engines are spark ignition (SI), port injection (PFI or GDI) and direct injection (DI) engines. In spark ignition engines, the injection pressure ranges from 2 to 3 bar and in direct injection engines from 100 to 200 bar. Diesel engines with direct injection operate at much higher pressures. These values are about 10 times or more than spark ignition engines. Injection systems are usually electronically controlled, since the opening and closing of the injector must be quick, which reduces fuel waste [13].

Liquid and gaseous fuels are burned only in a flare, and the liquid fuel is pre-sprayed into small droplets. The characteristics of the combustion process are influenced by several factors: the furnace design, the oxygen concentration of the supplied air for combustion, the pressure at which combustion occurs, etc. Combustion of liquid fuel is a multi-stage process.

Liquid fuel in the first stage is heated to boiling point and evaporates, and in the second stage, combustion occurs. The combustion scheme of a drop in liquid fuel is shown in Figure 1. Because the boiling point of liquid fuel is lower than the ignition temperature, its droplets first evaporate, and then the process of fuel combustion occurs. Because of diffusion through the resulting combustion products, air penetrates to the combustion surface. The combustion rate depends on the size of the burning surface, and the size of the burning surface depends on liquid fuel atomization: the finer the atomization, the greater the rate and completeness of combustion.

A combustion zone is established near the drop on a spherical surface, the diameter of which is $1-5$ times larger than the drop size. The droplet evaporates because of the heat of radiation from the combustion zone. In the space between the droplet and the combustion zone, there are liquid fuel vapors and combustion products, in the space outside the combustion zone - air and combustion products. Fuel vapor diffuses into the combustion zone from the inside, and oxygen from outside. Here, these components enter a chemical reaction, which is accompanied by the release of heat and the formation of combustion products.

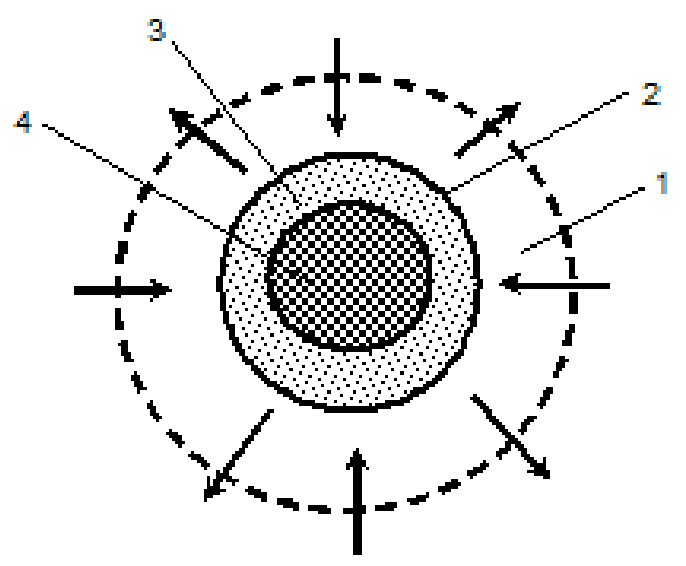

1 - area of diffusion of oxidizer and combustion products, 2 - liquid, 3 - fuel vapor, 4 - liquid fuel drop

Figure 1 - Scheme of the individual liquid fuel drops combustion

\section{Mathematical model of the problem}

In many experimental studies, it was found that many dimensionless scale parameters are involved in the primary sputtering process [14-16]. Among these parameters are the Weber and Reynolds numbers:

$$
\begin{gathered}
W e=\frac{\rho_{g}\left(u_{g, 0}-u_{l, 0}\right)^{2} D_{l}}{2 \sigma}, \\
\operatorname{Re}_{l}=\frac{u_{l, 0} D_{l}}{v_{l}}, \operatorname{Re}_{g}=\frac{u_{g, 0}\left(D_{g}-D_{l}\right)}{v_{g}},
\end{gathered}
$$

$u_{l, 0}$ is the inlet velocity of the liquid, $u_{g, 0}$ is the inlet velocity of the gas flow, $\sigma$ is the coefficient of surface tension, $D_{l}$ is liquid jet inlet diameter, $D_{g}$ is the inlet size of the concurrent gas jet. The main parameters also include the ratio of densities, mass and dynamic pressure of the gas and liquid phase: $\rho_{l} / \rho_{g}, \quad m=\frac{\rho_{g} u_{g, 0}\left(D_{g}^{2}-D_{l}^{2}\right)}{\rho_{l} u_{l, 0} D_{l}^{2}}$ and $M=\frac{\rho_{g} u_{g, 0}^{2}}{\rho_{l} u_{l, 0}^{2}}$. Of these three parameters, the last one is of primary importance, namely the ratio of impulses: 


$$
M=\frac{\rho_{g} u_{g, 0}^{2}}{\rho_{l} u_{l, 0}^{2}} .
$$

Inside the coaxial nozzle moving at a high speed gas flow forms a boundary layer at a rigid interface between two parallel gas and liquid flows. Dimensionless thickness of the incoming boundary layer is also a very important parameter:

$$
\frac{\delta_{g}}{D_{g}-D_{l}}
$$

We can also note the Onezorge number as another important parameter:

$$
O h=\frac{\mu_{l}}{\sqrt{\rho_{l} \sigma D_{l}}} .
$$

At the exit the boundary layer interacts with the liquid jet and leads to the Kelvin-Helmholtz instability on the free surface. According to the [17], the thickness of the incoming boundary layer controls the most unstable longitudinal wavelength of the Kelvin-Helmholtz instability $\delta_{g}$. At high Weber numbers, according to the [18], the instability wavelength $\lambda_{\mathrm{KH}}$ is:

$$
\lambda_{K H} \approx C_{K H} \sqrt{\frac{\rho_{l}}{\rho_{g}}} \delta_{g} .
$$

Here, for coaxial sputtering by an air flow $C_{K H}=2$, which corresponds to the measurements of the [17]. It can be used the Blasius transformations for the boundary layer thickness $\delta_{g}=C_{\delta} \frac{D_{g}-D_{l}}{2 \sqrt{\mathrm{Re}_{g}}}$ and the Reynolds number $\operatorname{Re}_{g}=\frac{u_{g, 0}\left(D_{g}-D_{l}\right)}{v_{g}}$ [19]. From, measurements of the [18] it was found that $C_{\delta}=5.6$.

The development of the Kelvin-Helmholtz instability is called the primary phase of instability. The outflowing jet depends on the large-scale instability of the flow. Then the waves of the primary instability are exposed to the gas flow then they are sped up. This leads to the rapid development of the Rayleigh-Taylor instability in the transverse direction $[20,21]$. The onset of this type of instability is called the secondary phase of instability. The expression for very long wavelengths with the Rayleigh-Taylor instability can be written as follows [21]:

$$
\lambda_{R T}=2 \pi \sqrt{\frac{3 \sigma}{\rho_{l} a}},
$$

where $\alpha$ means the free acceleration of the fluid. A rapidly moving gas, which produces primary droplets of size separate and fragment filaments of order:

$$
r \sim \frac{1}{2} \lambda_{R T}
$$

These droplets can be subjected to a secondary atomization process, forming an injection. It can be noted that discovered an important effect of the liquid injection rate on the droplet size. As for the typical droplet size in the far injection field, it is usually determined by the critical or maximum stable size when the destructive hydrodynamic forces are balanced by capillary forces:

$$
r_{c r}=W e_{c r} \sigma / \rho_{g} u_{r e l}{ }^{2} \text {, }
$$

where $u_{r e l}$ is the relative velocity between liquid and gas, $W e_{c r}$ is the critical Weber number, the value of which equals 6 large intervals of the Onezorge numbers [17].

The question is how to evaluate $u_{\text {rel }}$. Kolmogorov in his work assumes that a drop in a turbulent flow is stretched until the moment when this extension is of the order of the surface tension force [18]. It then evaluates the value $u_{r e l}$ from the expression for the typical increment of gas velocity in a uniform, steady-state turbulent flow. If $\varepsilon$ is the dissipation rate, then:

$$
r_{c r}=\frac{1}{2}\left(\frac{W e_{c r} \sigma}{\varepsilon^{2 / 3} \rho_{g}}\right)^{3 / 5} .
$$

These expressions do not consider the density of the liquid. A drop that moves in a turbulent flow will respond to its turbulent expansion only partially because of its inertia. The authors of works used the following expression [20, 22]: 


$$
\left\langle u_{r e l}^{2}\right\rangle \approx \varepsilon \tau_{s t},
$$

where $\tau_{s t}$ is the Stokes time:

$$
\tau_{S t}=\frac{2 \rho_{l} r^{2}}{9 \rho_{g} v_{g}} \frac{1}{1+0,15 \operatorname{Re}_{p} 0,687}
$$

Using this expression, one can assume:

$$
r_{c r}=\frac{1}{2}\left(\frac{W e_{c r} 18 v_{g} \sigma}{\varepsilon \rho_{l}}\right)^{1 / 3} .
$$

Both relations are valid when the post-spray mechanism is related to turbulence in the gas flow.

\section{Physical statement of the problem}

A model of a combustion chamber as a cylinder, the height of which is $15 \mathrm{~cm}$, diameter is $4 \mathrm{~cm}$ have been used. The general view of the combustion chamber is shown in Figure 2. The computational domain comprises 650 cells. Liquid fuel is injected by a nozzle in the center of the lower part of the combustion chamber. Temperature of the combustion chambers walls was $353 \mathrm{~K}$. The initial temperature of the gas in the combustion chamber was $700 \mathrm{~K}$, the fuel was injected at $300 \mathrm{~K}$. The initial radius of the injected droplets was 25 microns. Angle at which the droplets are injected was $10^{\circ}$. Pressure in the combustion chamber was 80 bar, the injection speed of the liquid fuel was $250 \mathrm{~m} / \mathrm{s}$.

In this work the simulation results of the processes of atomization, dispersion and combustion of liquid fuels in a cylindrical combustion chamber are presented. In this work, the liquid fuel dodecane is used. The chemical reaction of this fuel combustion in the chamber is presented below. This reaction leads to the formation of carbon dioxide and water:

$$
2 \mathrm{C}_{12} \mathrm{H}_{26}+37 \mathrm{O}_{2} \rightarrow 24 \mathrm{CO}_{2}+26 \mathrm{H}_{2} \mathrm{O} \text {. }
$$

The results of a numerical simulation of the dodecane combustion depending on the initial temperature of the oxidizer in the combustion chamber are presented. In the [23-27] works, similar studies were got by using numerical modeling at high turbulence, where the optimal values of pressure and mass for dodecane were determined. Thus, for dodecane at the initial moment of time, the values of pressure and mass were 80 bar and $7 \mathrm{mg}$. In this work, all calculations were got at optimal values of pressure and mass, which were taken from the works of the above authors, and the initial temperature in the combustion chamber varied from $700 \mathrm{~K}$ to $1500 \mathrm{~K}$.

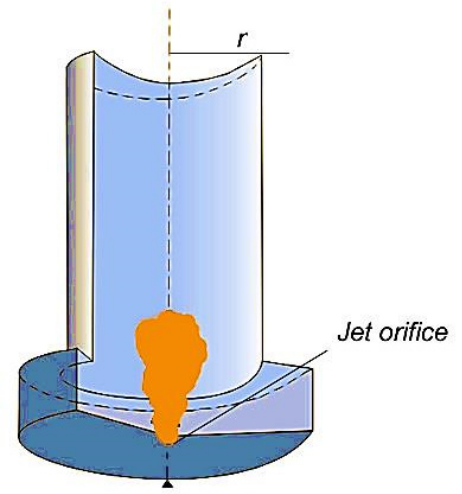

Figure 2 - General view of the combustion chamber

\section{Numerical simulation results}

Analysis of Figure 3 shows that if the temperature of the oxidizer in the combustion chamber takes values above $800 \mathrm{~K}$, then the fuel burns more intensively, a large amount of heat is released and the combustion chamber heats up to $3000 \mathrm{~K}$. In this case, the initial temperature of the oxidizer has the greatest effect on the combustion of dodecane since an increase in the initial temperature from $900 \mathrm{~K}$ to $1500 \mathrm{~K}$ leads to an increase in the maximum temperature from $2080.09 \mathrm{~K}$ to $2684.69 \mathrm{~K}$.

Figure 4 shows the distribution of the maximum concentration of carbon dioxide for dodecane depending on the initial temperature of the oxidizer in the combustion chamber. During the combustion of dodecane, the concentration of the formed carbon dioxide takes on large values. As seen from the figure, with an increase in temperature from $900 \mathrm{~K}$ to $1500 \mathrm{~K}$, the concentration of carbon dioxide released during the combustion of dodecane takes values from 0.11986 $\mathrm{g} / \mathrm{g}$ to $0.14142 \mathrm{~g} / \mathrm{g}$.

From the analysis of the curves in Figures 3 and 4 , it can be concluded that for dodecane, the optimal initial temperature of the oxidizer in the combustion chamber is $900 \mathrm{~K}$. At this temperature, the fuel quickly reacts with the oxidizer, the chamber heats to high temperatures, and the concentration of the resulting carbon dioxide does not exceed the permissible limits. 


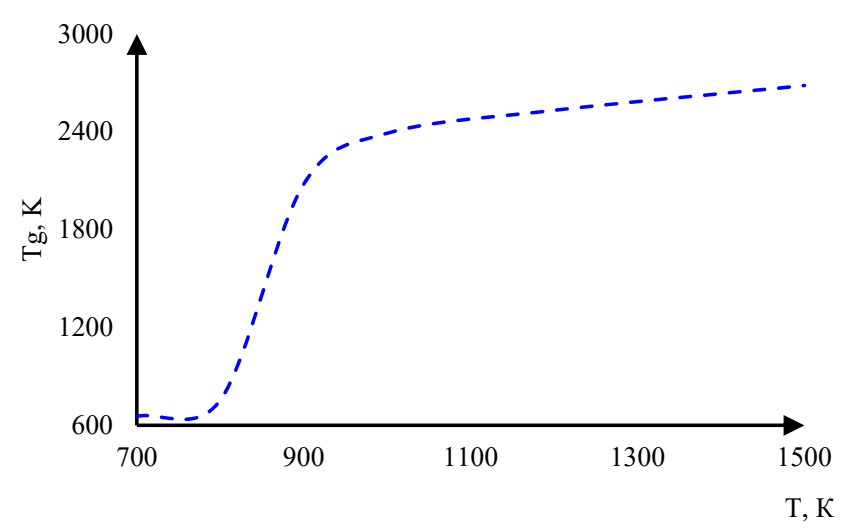

Figure 3 - Dependence of the maximum combustion temperature on the initial temperature of the oxidizer in the combustion chamber

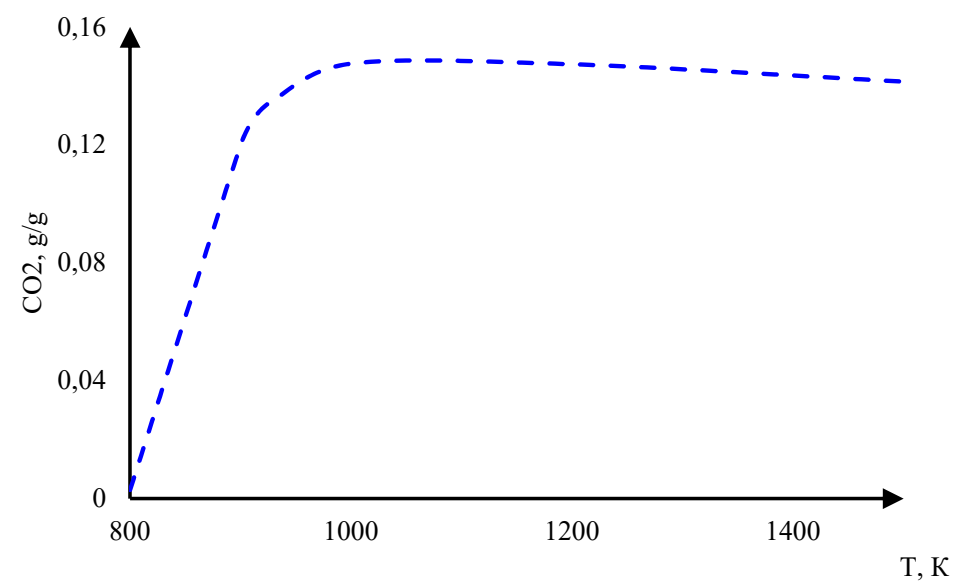

Figure 4 - Dependence of the concentration of the carbon dioxide $\mathrm{CO}_{2}$ on the initial temperature of the oxidizer during the dodecane combustion

It confirmed this conclusion by threedimensional graphs of the distribution of the main parameters describing the processes of breakup, dispersion and combustion of liquid fuel (dodecane), which are given below.

Figures 5-9 show the results of the computational experiments on the influence of the oxidizer temperature on the spray and combustion processes of the liquid fuel (dodecane). These graphs were obtained at the optimum oxidizer temperature in the combustion chamber equal to $900 \mathrm{~K}$.

Figure 5 shows the temperature distribution in the combustion chamber for dodecane at time $\mathrm{t}=2.5$ $\mathrm{ms}$ at an initial oxidizer temperature of $900 \mathrm{~K}$ and at optimal pressure and mass values. From these graphs, we can see how the temperature in the combustion chamber changes at a time. As seen from Figure 5 a, during the dodecane combustion, the region of maximum temperatures at time $\mathrm{t}=2.5$ $\mathrm{ms}$ reaches $3.6 \mathrm{~cm}$ along the height of the combustion chamber, the rest of the chamber heats to $1000 \mathrm{~K}$. The maximum temperature in the flame is $1526 \mathrm{~K}$ at this time of moment (Figure $5 \mathrm{a}$ ).

Figure $5 \mathrm{~b}$ shows a similar temperature distribution of dodecane at time $\mathrm{t}=3 \mathrm{~ms}$. When a mixture of fuel vapors with an oxidizer ignites, the fuel (dodecane) burns quickly. A large part of the chamber is covered in a torch across the width (Figure $5 \mathrm{~b}$ ). When dodecane burns, the maximum temperature is $2080 \mathrm{~K}$ (Figure $5 \mathrm{~b}$ ), i.e. the dodecane's torch has high temperatures, which confirms the results shown in Figure 3. 


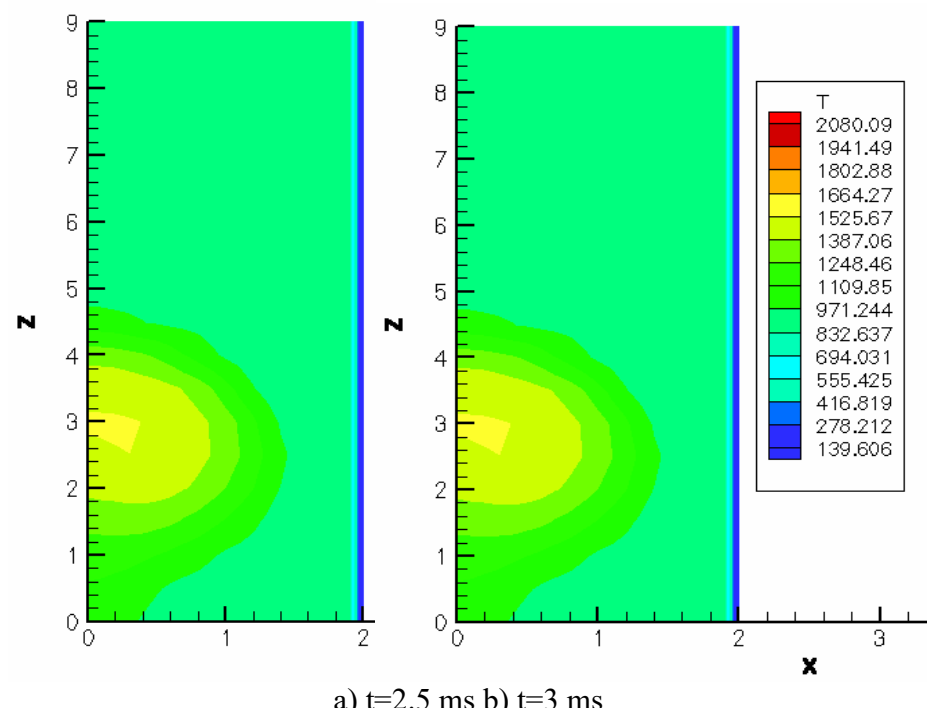

Figure 5 - Distribution of the temperature in the combustion chamber for dodecane at different times

Figures $6 \mathrm{a}$ and $6 \mathrm{~b}$ show the graphs of the distribution of liquid fuel injection droplets at the optimum temperature at different times. At the moment of time $t=2.5 \mathrm{~ms}$, dodecane drops are concentrated in a small region along the width of the combustion chamber. During the combustion of dodecane at the time $\mathrm{t}=2.5 \mathrm{~ms}$, the liquid fuel droplets reach $0.4 \mathrm{~cm}$ along the chamber height (Figure 6 a).

Figure $6 \mathrm{~b}$ shows the dispersion and temperature distribution of droplets for the dodecane in the combustion chamber at the initial optimum temperature at time $\mathrm{t}=3 \mathrm{~ms}$. Dodecane droplets lie at a height of $0.52 \mathrm{~cm}$. Fuel droplets are evenly distributed over the height and width of the combustion chamber. In this case, more drops with high temperatures are observed and the maximum temperature of its drops reaches $638.35 \mathrm{~K}$ (Figure $6 b)$.

Figure 7 shows the change the dodecane vapor concentration at the time $\mathrm{t}=2.5 \mathrm{~ms}$ at the initial oxidizer temperature equal to $900 \mathrm{~K}$ and at the optimal pressure and mass values.

At high turbulence, the area occupied by the fuel in the chamber decreases, which is consistent with the results of Figure 5 and 6 . At this time, on the axis of the chamber during the combustion of dodecane, fuel vapors rise to $3.8 \mathrm{~cm}$ along the height of the combustion chamber. In the rest of the chamber, the concentration of fuel vapors is minimal.

As can it be seen in the Figure 7, dodecane burns without residue, fuel vapor is almost zero. The minimum concentration of dodecane vapor at a time of $4 \mathrm{~ms}$ was $0.01 \mathrm{~g} / \mathrm{g}$.

Figures 8-9 show the results of numerical simulations of the distribution of combustion products and oxygen concentration on the chamber axis. The graphs of the distribution of the reaction products at the time instant of $3 \mathrm{~ms}$ are shown. So in Figure 8, we can observe how the oxygen concentration in the combustion chamber changes at a time of $3 \mathrm{~ms}$ during the initial oxidizer temperature of $900 \mathrm{~K}$ and we can say that in most of the combustion chamber at the temperature of $900 \mathrm{~K}$, the oxygen concentration is highest.

The maximum oxygen concentration during the combustion of dodecane is equal to $0.1875 \mathrm{~g} / \mathrm{g}$. However, the core of the torch, where the oxidant is consumed for fuel combustion, contains the smallest amount of oxygen: during the combustion of dodecane, the oxidant concentration is $0.05 \mathrm{~g} / \mathrm{g}$. When dodecane was burning, the oxygen consumption for fuel combustion was carried out at a height of $3.8 \mathrm{~cm}$ to $4.6 \mathrm{~cm}$. Analyzing this graph, one can make sure that the largest amount of oxygen is concentrated in the torch core during the combustion of the liquid fuel. 


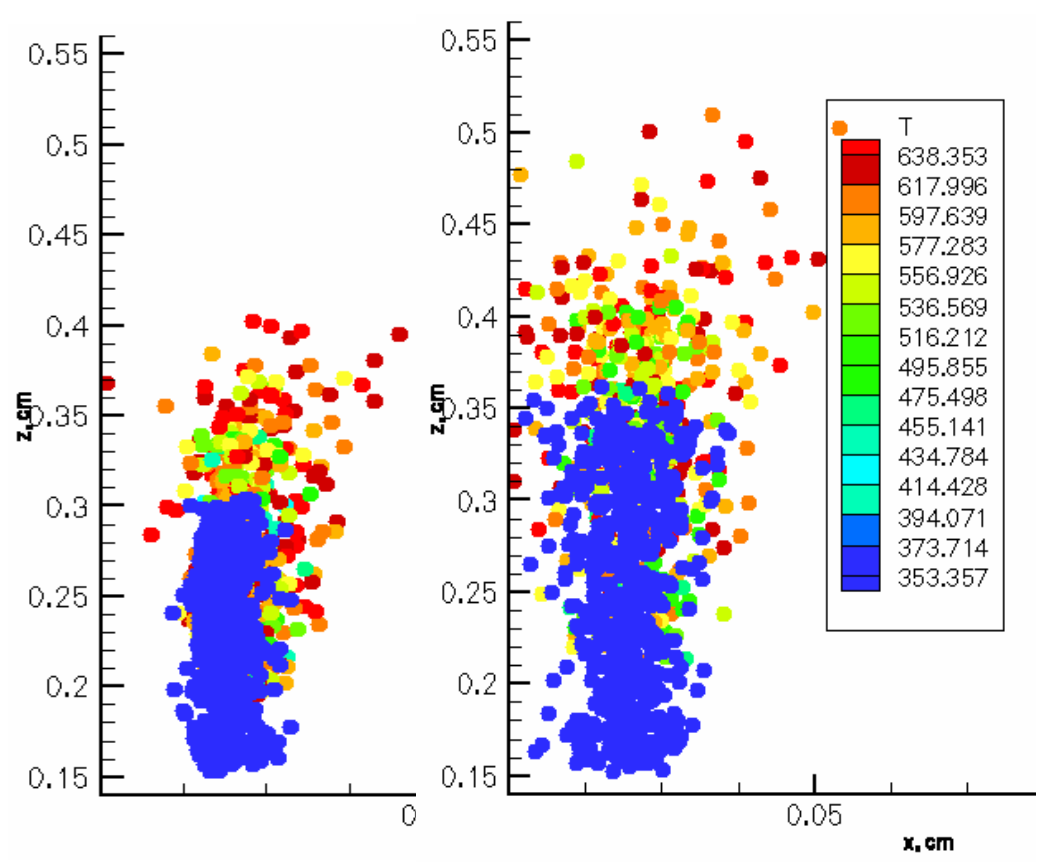

a) $\mathrm{t}=2.5 \mathrm{~ms} \mathrm{~b}) \mathrm{t}=3 \mathrm{~ms}$

Figure 6 - Distribution of temperature of the dodecane droplets in the combustion chamber

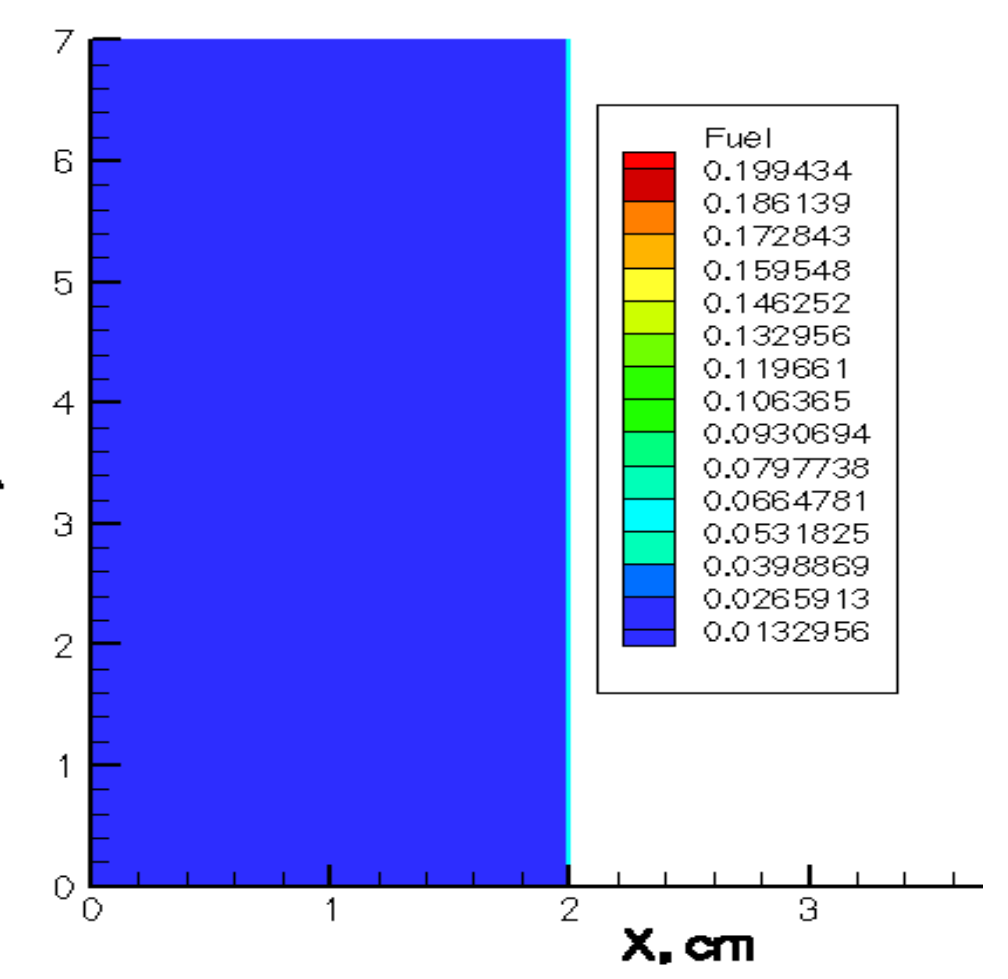

Figure 7 - Concentration field of the fuel vapor at $\mathrm{t}=2.8 \mathrm{~ms}$ 


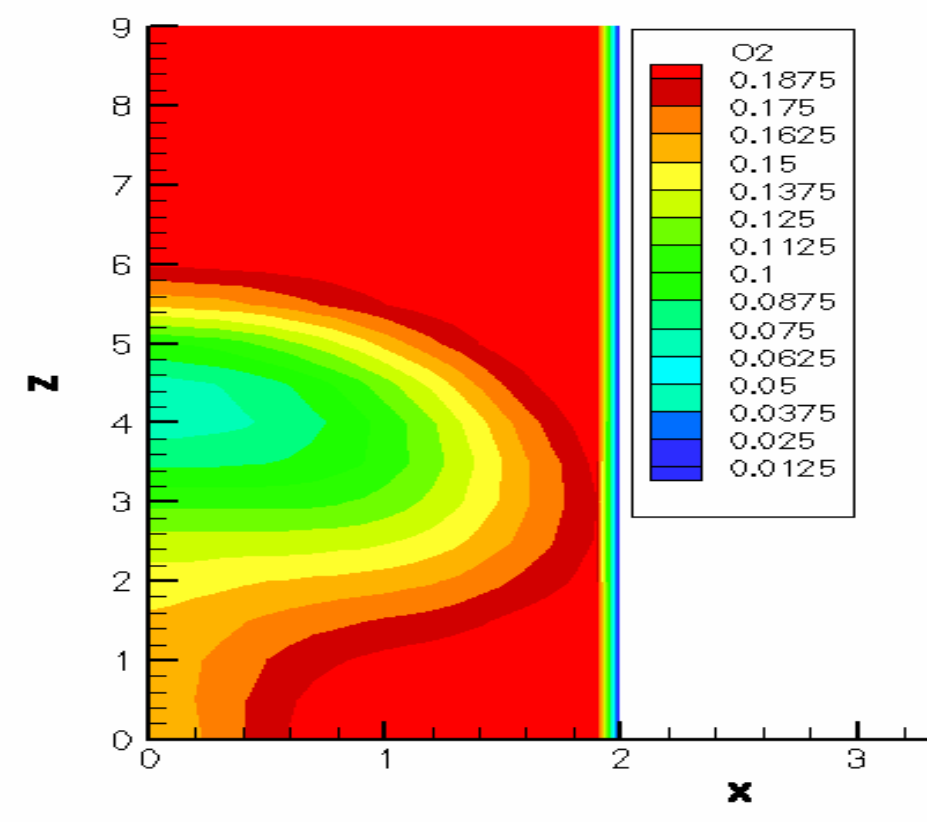

Figure 8 - Concentration field of the oxidizer $\mathrm{O}_{2}$ in the combustion chamber at the time $\mathrm{t}=3 \mathrm{~ms}$

Figures 9 and 10 show the graphs of the distribution of the concentrations of water and carbon dioxide at time $\mathrm{t}=3 \mathrm{~ms}$ for dodecane at an initial oxidizer temperature of $900 \mathrm{~K}$ and at optimal pressure (80 bar) and mass $(7 \mathrm{mg})$. Analysis of Figure 9 shows that at a time of $3 \mathrm{~ms}$, the maximum concentration of water resulting from the chemical reaction of dodecane combustion reached a value of $0.060256 \mathrm{~g} / \mathrm{g}$. In the remaining parts of the combustion chamber, the concentration of water reaches its lowest value, in most part of the combustion chamber, the minimum amount of moisture is maintained, which is equal to $0.00306837 \mathrm{~g} / \mathrm{g}$.

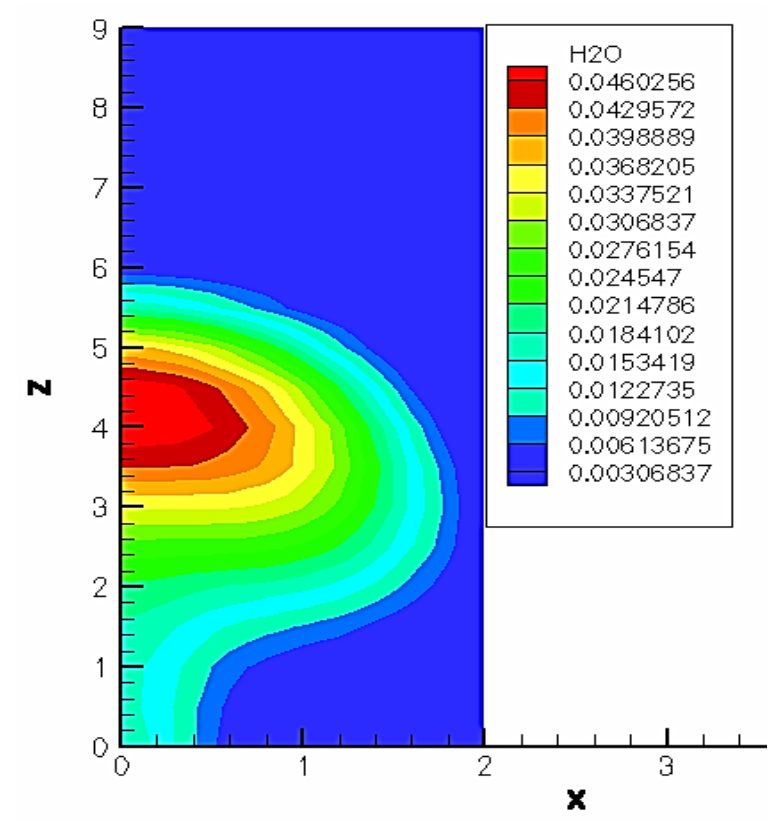

Figure 9 - Distribution of water vapor $\mathrm{H}_{2} \mathrm{O}$ during the combustion of dodecane in the combustion chamber at $\mathrm{t}=3 \mathrm{~ms}$ 
Figure 10 shows the results of numerical modeling of the formation of carbon dioxide during the combustion of dodecane at an optimal temperature of $900 \mathrm{~K}$. Analysis of the figure shows that the maximum amount of carbon dioxide for dodecane on the axis of the combustion chamber, the concentration of carbon dioxide reaches a value equal to $0.103878 \mathrm{~g} / \mathrm{g}$. At the exit from the combustion chamber, the concentration of carbon dioxide decreases and takes on minimum values. So, for dodecane at an optimal temperature of $900 \mathrm{~K}$, the concentration of carbon dioxide is $0.008 \mathrm{~g} / \mathrm{g}$.
Numerical simulation data were compared with the probability density function of droplet size distribution. At a distance of $40 \mathrm{~mm}$ from the injector nozzle at the center of one separate jet, this function is in good agreement with both experimental data and the results of numerical simulation.

Experimental [28-32] and numerical droplet size distributions were compared with two standard particle distribution functions that are often found in the technical literature. The first is the log normal distribution, and the second is the RosinRammler distribution (Figure 11).

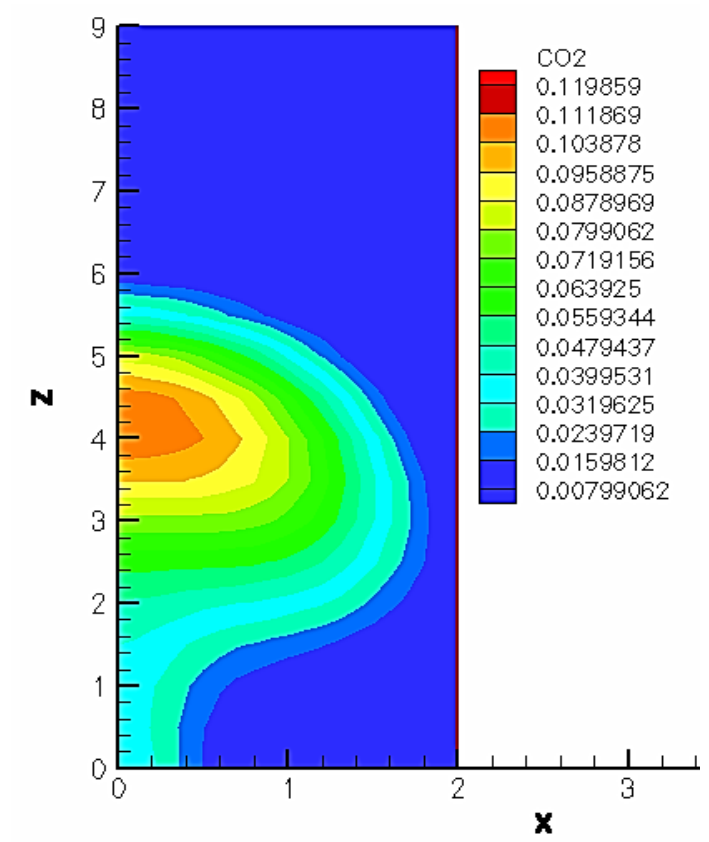

Figure 10 - Distribution of carbon dioxide $\mathrm{CO}_{2}$ concentrations during the combustion of dodecane at $\mathrm{t}=3 \mathrm{~ms}$

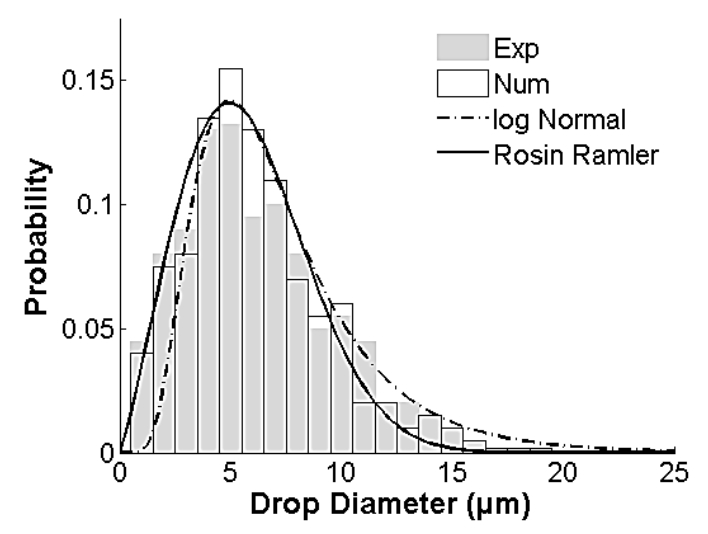

Figure 11 - Comparison of the probability function of droplet size distribution with experimental and numerical data 
In the experiment, we observed a time delay of $400 \mathrm{~ms}$ when the injector was switched on electrically and physically. This deceleration comprises an electrical and hydraulic time delay. This deceleration was considered in the numerical simulation so that the start time of fuel injection was identical to the experiment.

\section{Conclusions}

In this way, we presented the numerical study of the influence of the initial temperature of the oxidant on the combustion of dodecane in this article. The optimal parameters for the fuel mass and pressure in the combustion chamber, which was previously determined in [23-27] have been used. It was shown that for the investigated type of fuel (dodecane), the best initial temperature of the oxidizer in the combustion chamber is $900 \mathrm{~K}$. At this temperature, the fuel burns completely, the chamber heats to sufficiently high temperatures, and the concentration of the resulting carbon dioxide takes the lowest values.
Verification of the results obtained during computational experiments, comparison with experimental data and theoretical calculations, showed good agreement. This allows us to conclude that the mathematical model proposed in this work, which describes the breakup, dispersion, evaporation and combustion of liquid fuel injected into the combustion chamber at high turbulence, can be further used to study the processes of heat and mass transfer during multihole injection.

Obtained results can be used in the design of various internal combustion engines, which would simultaneously solve the problem of optimizing the combustion process, increasing the efficiency of fuel combustion and minimizing harmful emissions.

\section{Acknowledgments}

The Ministry of Education and Science of the Republic of Kazakhstan No. AP08857288 has supported financially this work.

\section{References}

1. A. Askarova, et al. Computational method for investigation of solid fuel combustion in combustion chambers of a heat power plant // High Temperature. - 2015. - Vol. 53. - P. 751-757. https://doi.org/10.1134/S0018151X15040021

2. V. Messerle, et al. Processes of heat and mass transfer in furnace chambers with combustion of thermochemically activated fuel // Thermophysics and Aeromechanics. - 2019. - Vol. 26. - P. 925-937. https://doi.org/10.1134/S0869864319060143

3. P. Safarik, et al. Optimization of the solid fuel combustion process in combustion chambers in order to reduce harmful emissions // News of the national academy of sciences of the Republic of Kazakhstan. Physical and mathematical series. - 2019. - Vol. 6. - p. 34-4. https://doi.org/10.32014/2019.2518-1726.71

4. Z. Gabitova, et al. Simulation of the aerodynamics and combustion of a turbulent pulverized-coal flame // 4th International Conference on Mathematics and Computers in Sciences and in Industry (MCSI 2017). - 2017. - Vol. 17668480. - P. 92-97. https://doi.org/10.1109/MCSI.2017.23

5. P. Safarik, A. Nugymanova, et al. 3D modeling of heat transfer processes in the combustion chamber of a TPP boiler // News of the national academy of sciences of the Republic of Kazakhstan. Physical and mathematical series. - 2019. - Vol. 6. - P. 5-13. http://dx.doi.org/10.32014/2019.2518-1726.68

6. A. Askarova, et.al. Numerical research of aerodynamic characteristics of combustion chamber BKZ-75 mining thermal power station // Procedia Engineering. - 2012. - Vol. 42. - P. 1250-1259. https://doi.org/10.1016/j.proeng.2012.07.517

7. M.M. Khan, J. Helie, M. Gorokhovski Computational methodology for non-evaporating spray in quiescent chamber using Large Eddy Simulation // International Journal of Multiphase Flow. - 2018. - Vol. 102. - P. 102-118. https://doi.org/10.1016/j.ijmultiphaseflow.2018.01.025

8. V. Messerle. A. Ustimenko, et al. Reduction of noxious substance emissions at the pulverized fuel combustion in the combustor of the BKZ-160 boiler of the Almaty heat electro power station using the "Overfire Air" technology // Thermophysics and Aeromechanics. - 2016. - Vol. 23. - P. 125-134. http://dx.doi.org/10.1134/S0869864316010133 
9. A. Bekmuhamet, et al. Mathematical simulation of pulverized coal in combustion chamber // Procedia Engineering. - 2012. - Vol. 42. - P. 1150-1156. https://doi.org/10.1016/j.proeng.2012.07.507

10. S. Bolegenova, Z. Gabitova, et al. Control harmful emissions concentration into the atmosphere of megacities of Kazakhstan Republic // IERI Procedia. - 2014. - Vol. 10. $\quad$ - P. 252-258. https://doi.org/10.1016/j.ieri.2014.09.085

11. A. Takeishi Knowledge Partitioning in the Interfirm Division of Labor: The Case of Automotive Product Development // Organization Science. - 2002. - Vol. 13. - P. 321-338. https://doi.org/10.1287/orsc.13.3.321.2779

12. C. Wang, J. Chen, J. Zou Decomposition of energy-related $\mathrm{CO}_{2}$ emission in China: 1957-2000// Energy. 2005. - Vol. 30. - P. 73-83. https://doi.org/10.1016/j.energy.2004.04.002

13. P. Safarik, et al. Numerical investigation of heat and mass transfer processes in the combustion chamber of industrial power plant boiler. Part 1. Flow field, temperature distribution, chemical energy distribution // Applied and Computational Mechanics. - 2017. - Vol. 11. - P. 115-128. http://dx.doi.org/10.24132/acm.2017.395

14. P. Safarik, et al. Investigation of heat and mass transfer processes in the combustion chamber of industrial power plant boiler. Part 2. Distribution of concentrations of $\mathrm{O}_{2}, \mathrm{CO}, \mathrm{CO}_{2}, \mathrm{NO} / /$ Journal of Applied and Computational Mechanics. - 2018. - Vol. 12. - P. 127-138. http://dx.doi.org/10.24132/acm.2018.396

15. D. Gao, N. Morley, V. Dhir Numerical simulation of wavy falling film flow using VOF method // Journal of Computational Physics. - 2003. - Vol. 192. - P. 624-642. https://doi.org/10.1016/j.jcp.2003.07.013

16. A. Askarova, et al. 3D-modelling of Kazakhstan low-grade coal burning in power boilers of thermal power plant with application of plasma gasification and stabilization technologies // Journal of Physics: Conference Series. 2019. - Vol. 126. - P. 12-22. http://dx.doi.org/10.1088/1742-6596/1261/1/012022

17. E. Villermaux Mixing and spray formation in coaxial jets // Journal of propulsion and power. - 1998. - Vol. 14, Issue 5. - P. 807-817. http://dx.doi.org/10.2514/2.5344

18. J.C. Lasheras, E.J Hopfinger Liquid jet instability and atomization in a coaxial gas stream // Annual Review of Fluid Mechanics. - 2000. - Vol. 32, Issue 1. - P. 275-308. https://doi.org/10.1146/annurev.fluid.32.1.275

19. B. Rongshan, et al. Research on the CFD numerical simulation of flash boiling atomization // Energy. 2018. - Vol. 165. - P. 768-781. https://doi.org/10.1016/j.energy.2018.09.143

20. P. Wang P, J. Fröhlich, V. Michelassi, W. Rodi Large-eddy simulation of variable-density turbulent axisymmetric jets // International Journal of Heat and Fluid Flow. - 2008. - Vol. 29, Issue 3. - P. 654-664. http://dx.doi.org/10.1016/j.ijheatfluidflow.2008.02.002

21. M. Gorokhovski, J. Jouanguy, A. Chtab-Desportes Stochastic model of the near-to-injector spray formation assisted by a high-speed coaxial gas jet // Fluid Dynamics Research. - 2009. - Vol. 41, Issue 3. - P. 15. http://dx.doi.org/10.1088/0169-5983/41/3/035509

22. M. Gorokhovski, M. Herrmann Modeling primary atomization // Annual Review of Fluid Mechanics. 2008. - Vol. 40. - P. 343-366. https://doi.org/10.1146/annurev.fluid.40.111406.102200

23. A. Askarova, et al. Stochastic simulation of the spray formation assisted by a high pressure // AIP Conference Proceedings. - 2010. - Vol. 1207. - P. 66-73. https://doi.org/10.1063/1.3366446

24. S. Bolegenova, Sh. Ospanova, et al. Investigation of various types of liquid fuel atomization and combustion processes at high turbulence // Journal of Engineering and Applied Sciences. - 2018. - Vol. 13. - P. 4054-4064. http://dx.doi.org/10.36478/jeasci.2018.4054.4064

25. M. Gorokhovski, V. Saveliev Analyses of Kolmogorov's model of breakup and its application into Lagrangian computation of liquid sprays under air-blast atomization // Physics of Fluids. - 2003. - Vol. 15. - P. 184192. http://dx.doi.org/10.1063/1.1527914

26. M. Gorokhovski, J. Helie, et al. Experimental and numerical study of flash boiling in gasoline direct injection sprays //Applied Thermal Engineering. - 2017. - Vol. 123. - P. 377-389. https://doi.org/10.1016/j.applthermaleng.2017.05.102

27. C. Arcoumanis, M. Gavaises, E. Giannadakis Modelling of cavitation in diesel injector nozzles // Journal of fluid mechanics. - 2008. - Vol. 616. - P. 153-193. http://dx.doi.org/10.1017/S0022112008003777

28. A. Wehrfritz, et al. Large Eddy Simulation of high-velocity fuel sprays: studying mesh resolution and breakup model effects for spray A // Atomization and Sprays. - 2013. - Vol. 23. - P. 419-442. http://dx.doi.org/10.1615/AtomizSpr.2013007342

29. M. Mojtabi, G. Wigley, J. Helie The effect of flash boiling on the atomization performance of gasoline direct injection multistream injectors // Atomization and Sprays. - 2014. - Vol. 24. - P. 467-493. http://dx.doi.org/10.1615/AtomizSpr.2014008296 
30. M. Zhang, M. Xu, Y. Zhang, W. Zeng Flow field evaluation of superheated fuel sprays using high-speed PIV // SAE Technical Papers. - 2011. - P. 1880-1890. https://doi.org/10.4271/2011-01-1880

31. G. Zhang, et al. Macroscopic characterization of flash-boiling multi-hole sprays using planar laser induced exciplex fluorescence technique. Part I. On-axis spray structure // Atomization and Sprays. - 2012. - Vol. 22. - P. 861-878. http://dx.doi.org/10.1615/AtomizSpr.2013006760

32. W. Zeng, et al. Laser sheet drop sizing of evaporating sprays using simultaneous LIEF/MIE techniques // Proceedings of the Combustion Institute. - 2013. - Vol. 34. - P. 1677-1685. https://doi.org/10.1016/j.proci.2012.07.061 